\title{
Modelagem matemática da desidratação osmo-convectiva da palma forrageira (Opuntia fícus-indica Mill) utilizando soluções mistas
}

\section{Mathematical modeling of osmo-convective dehydration of the cactus pear (Opuntia ficus-indica Mill) using mixed solutions}

\author{
Enaile Tavares da Silva ${ }^{1^{*}}$, Elaine Cristina Oliveira da Silva ${ }^{2}$, Rennan Pereira de Gusmão ${ }^{3}$, Julice Dutra Lopes ${ }^{4}$, Thaisa \\ Abrantes Souza Gusmão ${ }^{5}$
}

\begin{abstract}
Resumo: Objetivou-se nesse estudo avaliar a influência de pré-tratamentos osmóticos utilizando secagem convectiva complementar no processo de perda de água, ganho de sólidos e nos parâmetros de qualidade (cor, atividade de água e textura) de cladódios de palma forrageira. O Cladódio foi submetido à desidratação osmótica utilizando soluções mistas contendo 5\% de $\mathrm{NaCl}$ e concentrações de sacarose de 50 e $60{ }^{\circ}$ Brix, em diferentes proporções palma/solução $(1: 1,1: 4$ e $1: 10)$ a $40{ }^{\circ} \mathrm{C}$. Posteriormente foi realizada secagem convectiva a 50 e $60{ }^{\circ} \mathrm{C}$. Foram utilizados, para ajuste aos dados experimentais da secagem, os modelos matemáticos de Page, Henderson \& Pabis, Cavancanti Mata, Exponencial de Dois Termos e Midilli. O cladódio de palma in natura e desidratado foi caracterizado quanto aos parâmetros de cor, atividade de água e textura. O aumento da perda de massa foi proporcional ao aumento da proporção cladódio/solução utilizada na desidratação osmótica e o ganho de sólidos foi maior para a concentração de $50{ }^{\circ}$ Brix. O modelo matemático de Midilli foi o que melhor se ajustou aos dados experimentais. Os parâmetros de cor, atividade de água e textura foram modificados pelas condições de desidratação osmótica e de secagem as quais o cladódio de palma foi submetido. O cladódio desidratado a $50{ }^{\circ} \mathrm{C}$ apresentou melhor preservação da cor, maior resistência ao corte e menor atividade de água.
\end{abstract}

Palavras-chaves: Opuntia fícus indica Mill; modelo matemático; ganho de sólidos; secagem convectiva; desidratação osmótica.

\begin{abstract}
The objective of this study was to evaluate the influence of osmotic pre-treatments with complementary convective drying in the water loss process and solids gain of cactus pear cladodes, to obtain palm for human consumption. The cladode was subjected to osmotic dehydration using mixed solutions containing $5 \% \mathrm{NaCl}$ and sugar concentrations of 50 and $60{ }^{\circ} \mathrm{Brix}$ in different proportions palm/solution $(1: 1,1: 4$ and $1: 10)$ at $40{ }^{\circ} \mathrm{C}$. Subsequently convective drying was performed at 50 and $60{ }^{\circ} \mathrm{C}$. Were used to fit to the experimental data of drying, the mathematical models for Page, Henderson \& Pabis, Cavancanti Mata, Exponential of Two Terms and Midilli. The spineless cactus in natura and dehydrated was characterized as the parameters: color, water activity and texture. The study noted that the increased of weight mass was proportional to the increased of proportion cladode/solution used in osmotic dehydration and the solids gain was higher for concentration of 50 ${ }^{\circ}$ Brix. The Midilli mathematical model was the best fit to the experimental data. The parameters of color, water activity and texture were modified by the conditions of osmotic dehydration and drying which spineless cactus cladodes was submitted. The cactus cladode dehydrated at $50{ }^{\circ} \mathrm{C}$ presented better preservation of the color, increased cut resistance and lowest water activity.
\end{abstract}

Key words: Opuntia fícus indica Mill; mathematical model; solid gain; convective drying; osmotic dehydration.

\footnotetext{
*Autor para correspondência

Recebido para publicação em 30/06/2015; aprovado em 10/11/2015

${ }^{1}$ Engenheira de Alimentos, Universidade Federal de Campina Grande, Campina Grande; (83) 2101-1987, E-mail: enailetavares@ hotmail.com.

${ }^{2}$ Mestranda no Programa de Pós-graduação em Engenharia Agrícola, Universidade Federal de Campina Grande, E-mail: elaine-cristinna@hotmail.com

${ }^{3}$ Professor da Universidade Federal de Campina Grande, Unidade Acadêmica de Engenharia de Alimentos, E-mail: rennangusmao@gmail.com

${ }^{4}$ Professora da Universidade Federal de Campina Grande, Unidade Acadêmica de Engenharia de Alimentos, E-mail: julicedl@gmail.com

${ }^{54}$ Professora da Universidade Federal de Campina Grande, Unidade Acadêmica de Engenharia de Alimentos, E-mail: ta_brantes@hotmail.com
} 


\section{INTRODUÇÃO}

Devido às suas características, a palma forrageira (Opuntia fícus indica Mill), que se adapta morfofisiologicamente bem às condições adversas do semiárido, possui grande quantidade de água, é rica em resíduos minerais como cálcio, magnésio, sódio, potássio e vitaminas $\mathrm{A}, \mathrm{C}$ e do complexo $\mathrm{B}$ em quantidades muito superiores às encontradas em alimentos como repolho, couve, beterraba, banana e maçã, com a vantagem de ser um produto econômico e barato (BETANCOURT-DOMÍNGUEZ, 2006).

De acordo com Lima et al. (2012), o reconhecimento do valor nutricional da palma tem motivado o desenvolvimento de trabalhos técnicos, objetivando introduzir a verdura de palma na dieta alimentar da população. Várias pesquisas estão sendo desenvolvidas utilizando a palma forrageira nas formulações ou enriquecimento de produtos destinados à alimentação humana (CHOUGI et al., 2015; RAMÍREZMORENO et al., 2015). Tais iniciativas devem assumir papel fundamental nos programas sociais, na expectativa de reduzir a fome e minimizar as deficiências nutricionais da população.

A desidratação osmótica é uma técnica que tem sido utilizada como etapa preliminar ou adicional aos processos de secagem e congelamento, obtendo-se produtos de alta qualidade sensorial e nutricional, mais estáveis à contaminação microbiológica e à deterioração química (TORREGGIANI; BERTOLO, 2001). Em geral, o objetivo da desidratação osmótica é maximizar a perda de água, e ao mesmo tempo, minimizar o ganho de soluto por parte do sólido (QI et al., 1998). Contudo, a desidratação osmótica geralmente não é capaz de baixar a atividade de água a níveis que dispensem técnicas adicionais para conservação de alimentos. A secagem convectiva, por sua vez, diminui consideravelmente o teor de água no produto, o que minimiza o crescimento de microrganismos e reações de deterioração química, preservando-o durante a estocagem (MAYOR; SERENO, 2003), além de contribuir para a redução de custos de embalagem, transporte e armazenamento.

A secagem é atualmente empregada não apenas com o objetivo de conservação dos alimentos, mas também para elaboração de produtos diferenciados. A remoção parcial ou total de água promove a redução da massa e volume de produtos desidratados, implicando na inibição do crescimento microbiano e na prevenção de reações bioquímicas responsáveis pela deterioração do alimento, além de representar grandes vantagens quanto aos aspectos econômico e logístico, reduzindo os custos com embalagens, armazenamento e transporte (ALMEIDA et al., 2006; PONTES et al., 2007).

Segundo Dionello (2009), a combinação de métodos de preservação durante o processamento de alimentos visa à predominância das características originais do produto, possibilitando o aumento da vida de prateleira. As combinações de processos devem vir preferencialmente acompanhadas de redução no consumo de energia e no impacto sobre o meio ambiente, favorecendo a criação ou disponibilidade para consumo dos mais variados alimentos.

Diante dos aspectos mencionados, objetivou-se nesse estudo avaliar a influência de pré-tratamentos osmóticos utilizando secagem convectiva complementar no processo de perda de água, ganho de sólidos e nos parâmetros de qualidade (cor, atividade de água e textura) de cladódios de palma forrageira.

\section{MATERIAL E MÉTODOS}

Os experimentos foram realizados no Laboratório de Propriedades Físicas e no Laboratório de Armazenamento de Produtos Agrícolas da Universidade Federal de Campina Grande - Paraíba.

Para a realização dos experimentos foram utilizados cladódios da palma forrageira (Opuntia fícus indica Mill), adquiridos na cidade de Areia - PB, com teor de água inicial de aproximadamente $90 \%$ (b.u).

Os cladódios foram submetidas ao processo de limpeza utilizando água corrente e sanitizadas em solução clorada a 50 ppm por 15 minutos. O cladódio foi cortado em tiras, com dimensões 1,0 cm de largura, 10,0 cm de comprimento e 0,9 $\mathrm{cm}$ de espessura. Logo após o corte, pesaram-se quantitativos de 750 gramas da amostra para serem desidratadas nas condições utilizadas no estudo.

No preparo dos xaropes utilizou-se açúcar (sacarose) diluído em água potável, até atingir as concentrações de 50 e $60{ }^{\circ}$ Brix. Foi adicionado $\mathrm{NaCl}$ ao xarope na concentração de $5 \%$, em cada formulação estudada, formando assim uma solução mista. A desidratação osmótica foi realizada a partir da imersão dos cladódios na solução mista nas proporções de 1:1, 1:4 e 1:10 cladódio/solução. Os recipientes contendo os cladódios imersos na solução foram colocados em estufa a 40 ${ }^{\circ} \mathrm{C}$.

Para o acompanhamento da perda de água e do ganho de sólidos do cladódio da palma, foram identificadas três fatias de cladódio e colocadas em recipientes de alumínio dentro da solução. O tempo de imersão foi de 3 horas. Nos tempos de pesagem, as amostras identificadas foram retiradas da solução, lavadas com água destilada para retirada do filme de sacarose, secas com papel absorvente, pesadas e devolvidas à solução. Simultaneamente a esse processo, amostras foram retiradas, em duplicata, colocadas em cadinhos previamente secos e levadas à estufa para a determinação do teor de água final. O teor de água foi determinado, segundo metodologia do INSTITUTO ADOLFO LUTZ (2008).

O cálculo da porcentagem de água a cada tempo foi calculado pela seguinte fórmula:

$$
\mathrm{PP}(\%)=100 \times\left(\frac{\mathrm{P}_{\mathrm{o}}-\mathrm{P}_{\mathrm{t}}}{\mathrm{P}_{\mathrm{o}}}\right)
$$

Em que:

PP (\%) - Perda de massa, em \% (p/p);

$\mathrm{P}_{\mathrm{o}}-$ Peso do material vegetal no tempo $\mathrm{t}=0(\mathrm{~g})$;

$\mathrm{P}_{\mathrm{t}}-$ Peso do material vegetal tratado no tempo $\mathrm{t}(\mathrm{g})$.

A porcentagem de ganho de sacarose foi calculada pela fórmula:

$$
\mathrm{Gs}(\%)=100 \times\left(\frac{\mathrm{Ms}_{\mathrm{t}}-\mathrm{Ms}_{\mathrm{o}}}{\mathrm{P}_{\mathrm{o}}}\right)
$$

Em que:

Gs $(\%)$ - Ganho de sólidos, em \% (p/p);

$\mathrm{MS}_{\mathrm{t}}$ - Matéria seca do material vegetal no tempo $\mathrm{t}(\mathrm{g})$;

$\mathrm{MS}_{\mathrm{o}}-$ Matéria seca do material vegetal no $\mathrm{t}=0(\mathrm{~g})$. 
Os cladódios foram submetidos à secagem convectiva, utilizando o método empregado por Ferreira e Pena (2010), com algumas modificações. Os ensaios de secagem foram realizados em secador convectivo, em triplicata, utilizando temperaturas de 50 e $60{ }^{\circ} \mathrm{C}$, onde pesou-se em média $50 \mathrm{~g}$ de palma desidratada, nas duas concentrações (50 e $60^{\circ}$ Brix) e nas três proporções utilizadas na desidratação osmótica (1:1, 1:4 e 1:10), totalizado 12 amostras. Após pesagem as amostras foram dispostas em cestas de alumínio de peso conhecido e em seguida colocadas em secador convectivo para secagem.

Durante os primeiros $30 \mathrm{~min}$ de secagem foram realizadas pesagens do conjunto (bandeja e amostra) em intervalos de $5 \mathrm{~min}$. Nos $30 \mathrm{~min}$ seguintes as pesagens foram feitas a cada $10 \mathrm{~min}$. A partir deste tempo as pesagens foram feitas a cada 15 min por $1 \mathrm{~h}$. Em seguida foram realizadas pesagens a cada 30 min durante $2 \mathrm{~h}$, logo após a cada $1 \mathrm{~h}$, até peso constante.

As curvas foram determinadas em dois níveis de temperatura $\left(50\right.$ e $\left.60{ }^{\circ} \mathrm{C}\right)$ em três repetições. Os dados experimentais foram expressos na forma de razão de umidade $(\mathrm{RX})$ :

$$
R X=\frac{X-X_{e}}{X_{o}-X_{e}}
$$

Em que:

$\mathrm{X}$ - teor de água no instante $\mathrm{t}$, base seca, bs;

$\mathrm{X}_{\mathrm{e}}$ - teor de água de equilíbrio, bs;

$\mathrm{X}_{\mathrm{o}}$ - teor de água inicial, bs.

Os modelos de regressão não-linear de Page, Henderson e Pabis, Cavalcanti-Mata, Exponencial de Dois Termos e Midilli, descritos na Tabela 1 , foram ajustados aos dados experimentais da secagem do cladódio da palma forrageira. Os coeficientes dessas equações foram obtidos mediante ajuste das curvas de secagem aos dados experimentais, utilizando-se o software computacional Statistica, versão 7.0 (STATSOFT, 2004).

Como critério para determinação do modelo que melhor representou os dados experimentais, foram utilizados coeficiente de determinação $\left(\mathrm{R}^{2}\right)$ e o desvio quadrático médio (DQM), descrito na Equação 4.

$$
\mathrm{DQM}=\sqrt{\frac{\sum\left(\mathrm{RX}_{\mathrm{exp}}-\mathrm{RX}_{\mathrm{pre}}\right)^{2}}{\mathrm{~N}}}
$$

\author{
Em que: \\ DQM - desvio quadrático médio; \\ $\mathrm{RX}_{\text {pré - razão de umidade predita; }}$ \\ $\mathrm{RX}_{\text {exp }}$ - razão de umidade experimental; \\ $\mathrm{N}$ - número de dados experimentais.
}

Os parâmetros de cor das amostras foram determinados utilizando-se espectrofotômetro MiniScan HunterLab XE Plus, no sistema de cor Cielab. O instrumento, equipado com iluminante $\mathrm{D} 65 / 10^{\circ}$, foi calibrado com placa preta e placa branca padrão $(X=80,5 ; Y=85,3 ; Z=90,0)$, conforme instruções do fabricante. Foi determinado o parâmetro de L* luminosidade.

A determinação da resistência ao corte foi realizada, em cinco repetições, em pedaços de $6 \mathrm{~cm}$ de comprimento, cortados ao meio no sentido longitudinal de cada amostra. Utilizou-se o texturômetro TA.XT Plus Texture Analyser, operando com medida de força em compressão e probe Warner-Bratzler Blade HDP BSW, com velocidade de $20 \mathrm{~mm}$ $\mathrm{s}^{-1}$ e distância de $40 \mathrm{~mm}$.

Os valores de resistência ao corte foram analisados estatisticamente utilizando-se os procedimentos do programa estatístico SAS - Statistical Analysis System, versão 9.2.

Os dados da atividade de água, cor e textura foram submetidos à análise de variância (ANOVA) e ao teste de médias Tukey $(\mathrm{p} \leq 0,05)$.

\section{RESULTADOS E DISCUSSÃO}

Na Figura 1 encontra-se a perda de massa (A) e ganho de sólidos (B) ocorrida durante a desidratação do cladódio da palma forrageira à $40{ }^{\circ} \mathrm{C}$, nas três proporções $(1: 1,1: 4 \mathrm{e}$ 1:10) e nas duas concentrações estudadas (50 e $60{ }^{\circ}$ Brix).

Analisando a Figura 1A, verificou-se que as características do produto foram influenciadas pela concentração e proporção cladódio/solução do meio osmótico utilizado, com maior perda de massa ocorrendo na concentração de $60^{\circ}$ Brix e proporção $1: 1$ e menor perda de massa na concentração de $60{ }^{\circ}$ Brix e proporção 1:4. Observou-se em todas as concentrações que quanto maior a proporção cladódio/solução maior a perda de água, exceto para a proporção $1: 1$ da concentração de $60^{\circ}$ Brix, que obteve a maior perda de água. Verificou-se também que quanto maior foi a concentração de sólidos menor foi a perda de massa, exceto para a proporção $1: 1$ da concentração de 60 ${ }^{\circ}$ Brix.

\begin{tabular}{|c|c|}
\hline Modelo & Equação \\
\hline Page (1949) & $\mathrm{RX}=\exp \left(-\mathrm{kt}^{\mathrm{n}}\right)$ \\
\hline Henderson \& Pabis (1961) & $\mathrm{RX}=\mathrm{a} \exp (-\mathrm{kt})$ \\
\hline Cavalcanti-Mata (1998) & $\mathrm{RX}=\mathrm{a} 1 \operatorname{Exp}\left(-\mathrm{b} \mathrm{t}^{\mathrm{a} 2}\right)+\mathrm{a} 3 \operatorname{Exp}\left(-\mathrm{b} \mathrm{t}^{\mathrm{a} 4}\right)+\mathrm{a} 5$ \\
\hline Exponencial de Dois Termos (TOGRUL; PEHLIVAN, 2003) & $R X=a \exp \left(-k_{0} t\right)+b \exp \left(-k_{1} . t\right)$ \\
\hline Midilli et al. (2002) & $\mathrm{RX}=\mathrm{a} \exp \left(-\mathrm{k} \mathrm{t}^{\mathrm{n}}\right)+\mathrm{bt}$ \\
\hline
\end{tabular}

Tabela 1 - Modelos de regressão não-linear utilizados para ajuste aos dados experimentais

$\mathrm{RX}$ - razão de umidade, adimensional; $\mathrm{t}$ - tempo de secagem (min); $\mathrm{k}$ - constantes de secagem; a1, a2, a3, a4 e a5 e n - coeficientes dos modelos.

Analisando a Figura 1B, constatou-se que o ganho de sólidos foi maior para a concentração de $60{ }^{\circ}$ Brix. A concentração de sacarose quando aumentada diminui a perda de massa e o ganho de sólido pela viscosidade apresentada 
pela solução. Sousa et al. (2003), verificaram perda de massa mais elevada com a proporção da solução 1:4 comparada a proporção 1:2, ao estudar a influência da concentração e da proporção fruto/xarope na desidratação osmótica de bananas. Já Medeiros et al. (2006), observaram que na concentração de $50{ }^{\circ}$ Brix a perda de massa foi mais elevada que na concentração de $20{ }^{\circ}$ Brix, estudando o processo de desidratação osmótica da fruta da palma (figo da Índia). Ferrari et al. (2005), observaram uma diminuição da incorporação de sacarose com o aumento da concentração da solução, ao estudar a cinética de transferência de massa de melão desidratado osmoticamente em soluções de sacarose e maltose. Os autores atribuem esta redução ao fato de soluções mais concentradas limitarem a entrada de sólidos no produto, pela formação de uma camada superficial de açúcar ao redor da fruta.

Nas Figuras 2, 3, 4, 5 e 6 se encontram as curvas obtidas pelo ajuste dos modelos de Page, Henderson \& Pabis, Cavalcanti-Mata, Exponencial de Dois Termos e Midilli aos dados experimentais da secagem da palma forrageira, nas temperaturas de 50 e $60{ }^{\circ} \mathrm{C}$ e nas Tabelas 2 a 6 estão os parâmetros estimados para os referidos modelos com seus respectivos coeficientes de determinação $\left(R^{2}\right)$ e desvios médios quadráticos.

Figura 1. Percentual de perda de massa (A) e ganho de sólidos (B) dos cladódios de palma forrageira durante desidratação osmótica à temperatura de $40^{\circ} \mathrm{C}$.
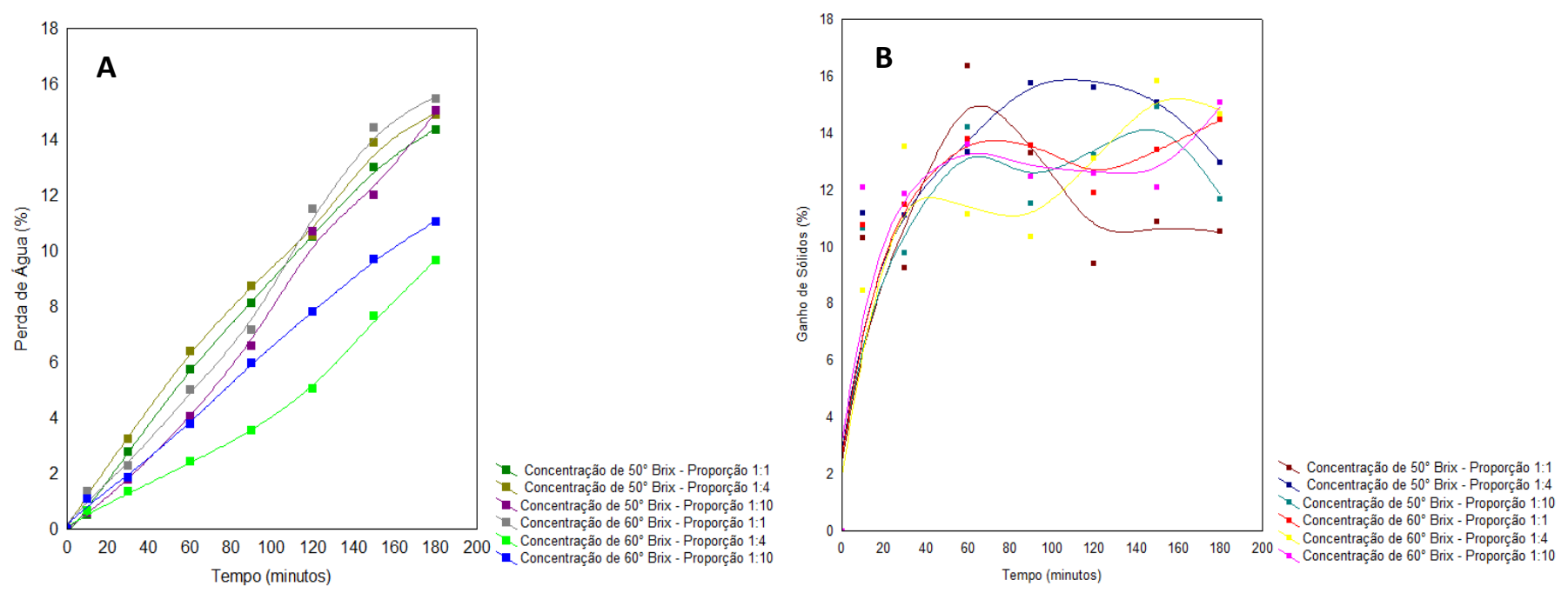

Figura 2 - Curvas obtidas pelo ajuste do modelo de Page aos dados experimentais da secagem dos cladódios da palma forrageira, nas temperaturas de 50 e $60{ }^{\circ} \mathrm{C}$.
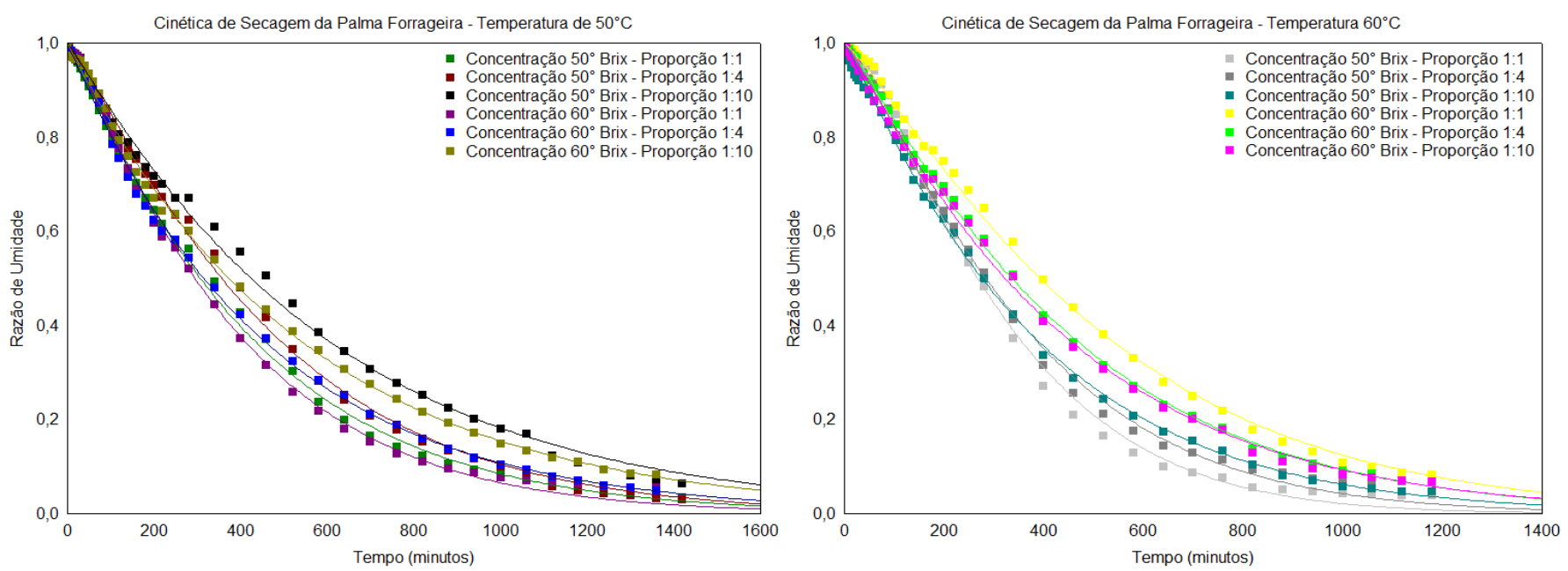
Figura 3 - Curvas obtidas pelo ajuste do modelo de Henderson \& Pabis aos dados experimentais da secagem dos cladódios da palma forrageira, nas temperaturas de 50 e $60^{\circ} \mathrm{C}$.
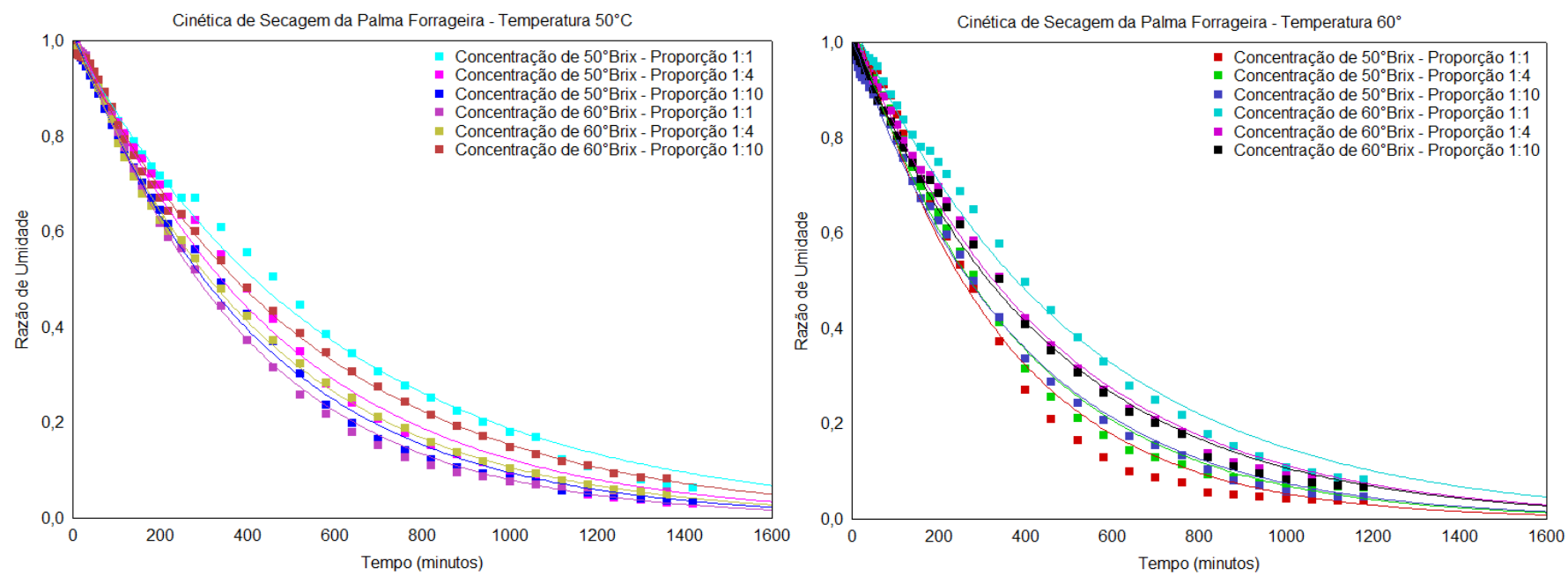

Figura 4 - Curvas obtidas pelo ajuste do modelo de Cavalcanti-Mata aos dados experimentais da secagem dos cladódios da palma forrageira, nas temperaturas de 50 e $60{ }^{\circ} \mathrm{C}$.
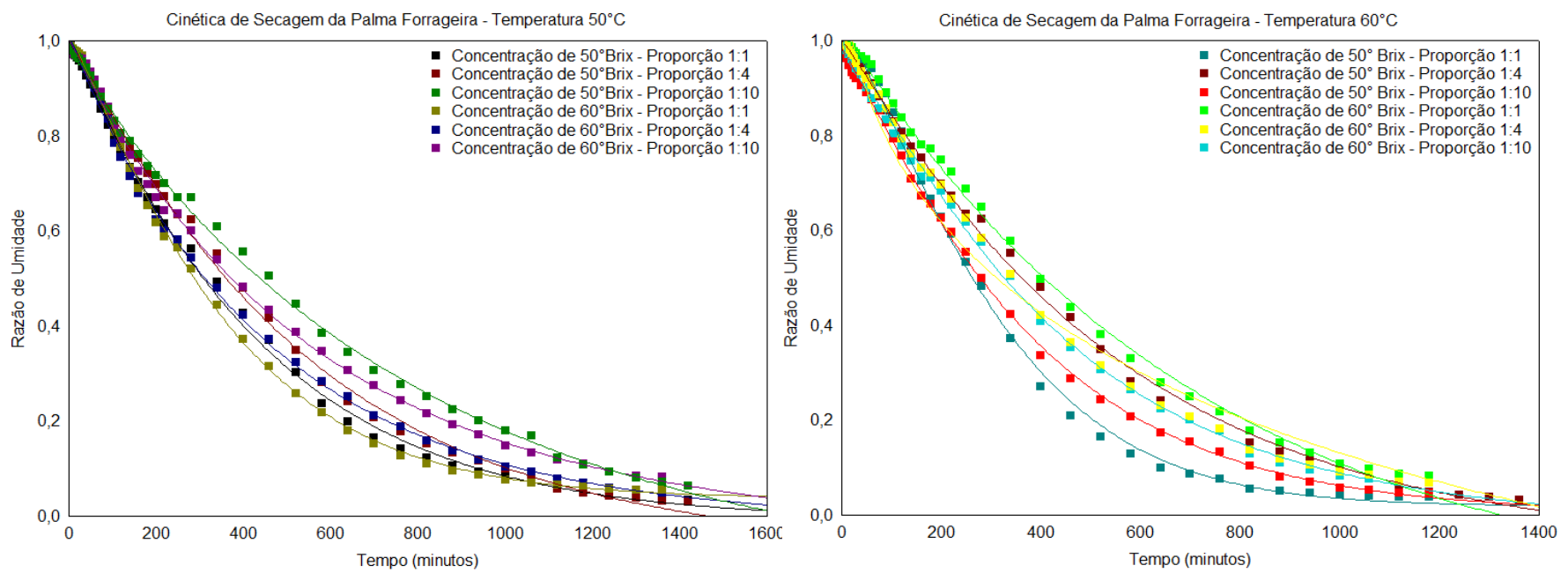

Figura 5 - Curvas obtidas pelo ajuste do modelo Exponencial de Dois Termos aos dados experimentais da secagem do cladódio da palma forrageira, nas temperaturas de 50 e $60{ }^{\circ} \mathrm{C}$.
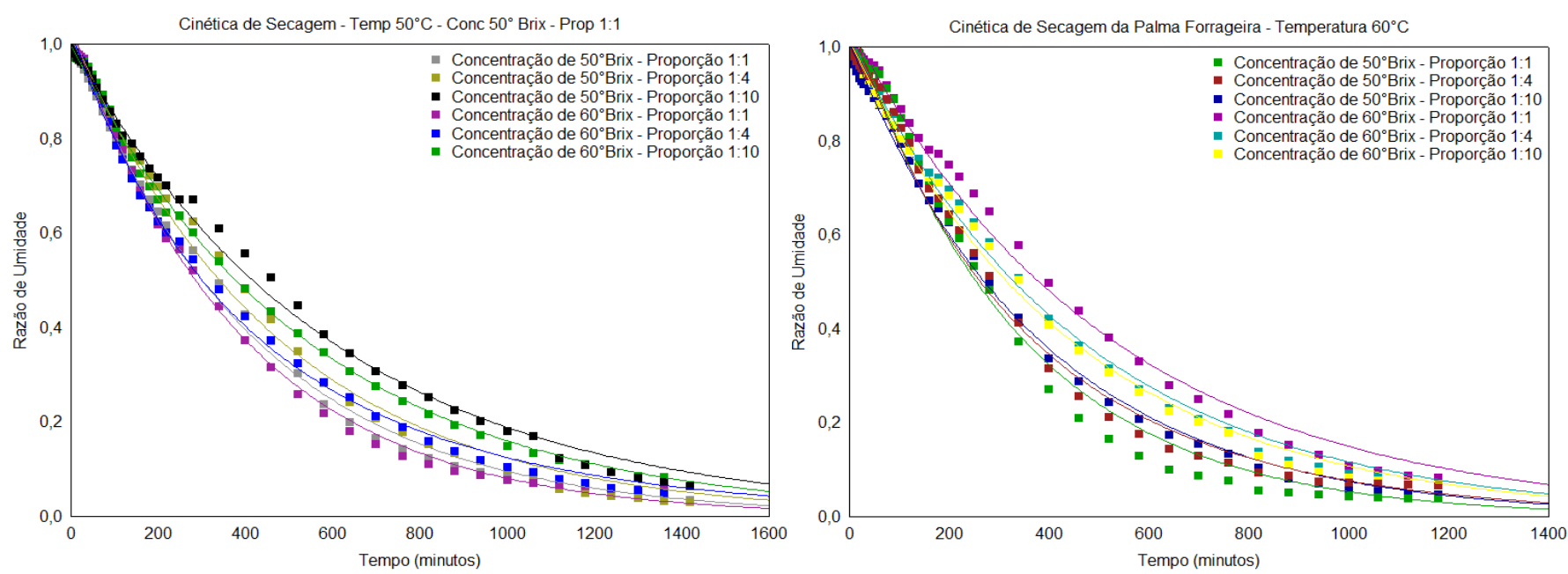
Figura 6 - Curvas obtidas pelo ajuste do modelo de Midilli aos dados experimentais da secagem dos cladódios da palma forrageira, nas temperaturas de 50 e $60{ }^{\circ} \mathrm{C}$.

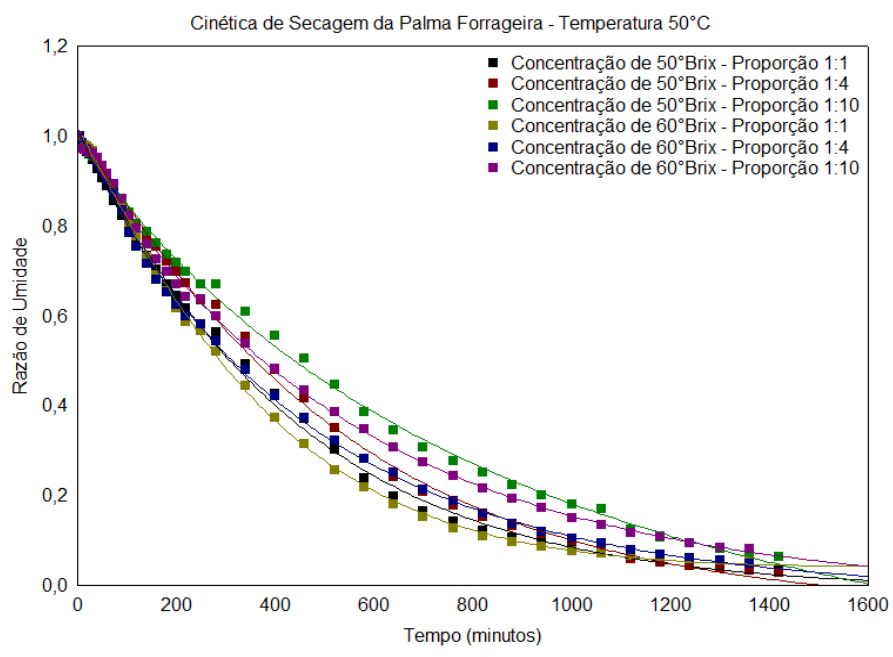

Analisando as Figuras 2, 3, 4, 5 e 6 pode-se observar que durante a secagem convectiva do cladódio da palma forrageira à medida que a temperatura é elevada, ocorre maior remoção de água do produto, além da redução do tempo de secagem, permitindo que o produto atinja o teor de água de equilíbrio mais rápido. Esse mesmo comportamento foi verificado por Corrêa et al. (2008), no estudo da desidratação osmótica de tomate seguida de secagem.

Na temperatura de $50{ }^{\circ} \mathrm{C}$ o tempo necessário para atingir peso constante foi de aproximadamente 1400 minutos (23 horas) para todos os tratamentos. Já na temperatura de $60{ }^{\circ} \mathrm{C}$, o tempo necessário para a palma atingir peso constante foi, em média, 1200 minutos (20 horas).

$\mathrm{Na}$ temperatura de $50{ }^{\circ} \mathrm{C}$ tem-se que o maior teor de água final foi observado na concentração de $50{ }^{\circ}$ Brix e proporção 1:10, já o menor teor de água final foi observado na concentração de $60{ }^{\circ}$ Brix e proporção $1: 1$. Observou-se que quanto menor a proporção de cladódio/solução em que o cladódio foi desidratado osmoticamente, menor o teor de água

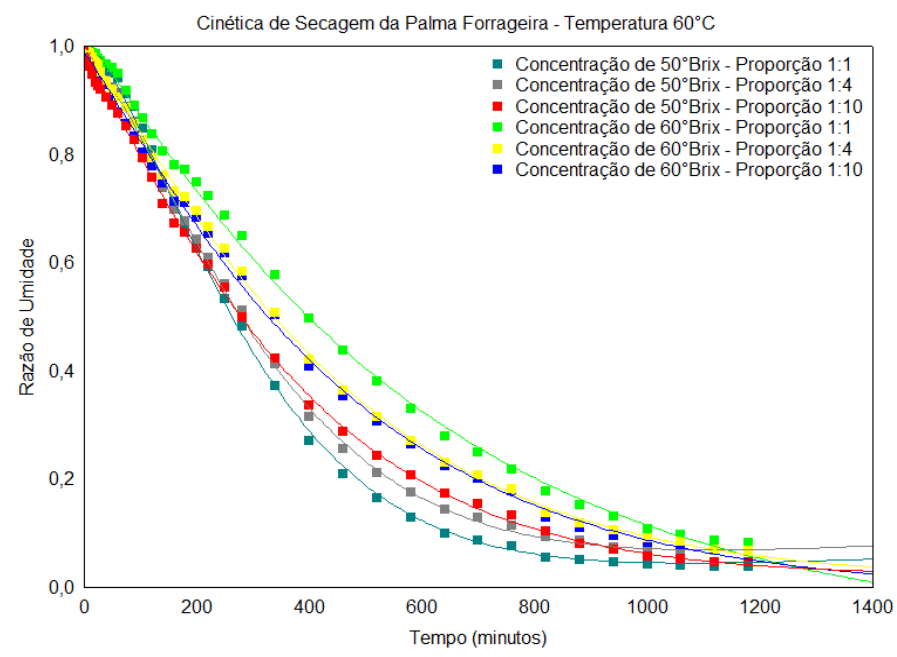

após a secagem convectiva. Observando as amostras submetidas à desidratação osmótica na mesma proporção cladódio/solução, verificou-se que na concentração de 60 ${ }^{\circ}$ Brix o teor de água final foi menor, ou seja, aumentando-se a concentração de solutos diminui-se a razão de umidade. $\mathrm{O}$ mesmo comportamento foi observado no estudo feito por Gonçalves e Blume (2008) sobre desidratação osmótica usada como tratamento preliminar na secagem de abacaxi.

$\mathrm{Na}$ temperatura de $60{ }^{\circ} \mathrm{C}$ tem-se que o maior teor de água final foi observado na concentração de $60{ }^{\circ}$ Brix e proporção $1: 1$, enquanto que o menor teor de água foi verificado na concentração de $50{ }^{\circ}$ Brix e proporção $1: 1$. Em ambas as concentrações foi observado que quanto maior a proporção de cladódio/solução maior o teor de água final, exceto para a concentração de $60{ }^{\circ}$ Brix e proporção $1: 1$, que apresentou o maior teor de água final. Verificou-se que a concentração de $50^{\circ}$ Brix apresentou menor teor de água final em relação à concentração de $60^{\circ}$ Brix.

Tabela 2 - Coeficientes obtidos pelo ajuste do modelo de Page aos dados experimentais da secagem dos cladódios de palma forrageira, nas temperaturas de 50 e $60{ }^{\circ} \mathrm{C}$.

\begin{tabular}{|c|c|c|c|c|}
\hline \multirow[t]{2}{*}{ Formulação } & \multicolumn{2}{|c|}{ Parâmetros } & \multirow[t]{2}{*}{$\begin{array}{c}\mathrm{R}^{2} \\
(\%) \\
\end{array}$} & \multirow[t]{2}{*}{ DQM } \\
\hline & $\mathrm{k}$ & $\mathrm{n}$ & & \\
\hline $50{ }^{\circ} \mathrm{C}-50{ }^{\circ} \mathrm{Brix}-1: 1$ & 0,0014 & 1,0770 & 0,9994 & 0,0673 \\
\hline $50{ }^{\circ} \mathrm{C}-50^{\circ}$ Brix $-1: 4$ & 0,0008 & 1,1456 & 0,9993 & 2,3666 \\
\hline $50^{\circ} \mathrm{C}-50{ }^{\circ} \mathrm{Brix}-1: 10$ & 0,0012 & 1,0494 & 0,9987 & 2,7186 \\
\hline $50^{\circ} \mathrm{C}-60^{\circ}$ Brix $-1: 1$ & 0,0012 & 1,1190 & 0,9990 & 3,4425 \\
\hline $50{ }^{\circ} \mathrm{C}-60^{\circ}$ Brix $-1: 4$ & 0,0021 & 1,0090 & 0,9993 & 1,1879 \\
\hline $50^{\circ} \mathrm{C}-60^{\circ}$ Brix $-1: 10$ & 0,0018 & 1,0060 & 0,9994 & 0,4081 \\
\hline $60{ }^{\circ} \mathrm{C}-50{ }^{\circ}$ Brix $-1: 1$ & 0,0005 & 1,2981 & 0,9986 & 3,4131 \\
\hline $60{ }^{\circ} \mathrm{C}-50{ }^{\circ} \mathrm{Brix}-1: 4$ & 0,0008 & 1,2055 & 0,9986 & 2,2854 \\
\hline $60^{\circ} \mathrm{C}-50^{\circ}$ Brix $-1: 10$ & 0,0016 & 1,0786 & 0,9994 & 1,8639 \\
\hline $60{ }^{\circ} \mathrm{C}-60^{\circ}$ Brix $-1: 1$ & 0,0006 & 1,1766 & 0,9994 & 1,6776 \\
\hline $60{ }^{\circ} \mathrm{C}-60^{\circ}$ Brix $-1: 4$ & 0,0010 & 1,1259 & 0,9997 & 0,2390 \\
\hline $60^{\circ} \mathrm{C}-60^{\circ}$ Brix $-1: 10$ & 0,0013 & 1,0897 & 0,9993 & 1,2931 \\
\hline
\end{tabular}

Analisando a Tabela 2, percebe-se que o modelo de Page se ajustou satisfatoriamente aos dados experimentais apresentando coeficientes de determinação variando de
$99,87 \%\left(50{ }^{\circ} \mathrm{C}\right)$ a $99,97 \%\left(60{ }^{\circ} \mathrm{C}\right)$ e desvio médio quadrático menor que 3,45 para todas as temperaturas. Porto et al. (2014) ao avaliarem a secagem da uva Crimson Seedles pré-tratada 

soluções mistas

osmoticamente verificaram que o modelo matemático de Page se ajustou melhor aos dados experimentais de secagem com $\mathrm{R}^{2}$ igual a 0,995. Silva et al. (2003) ao aplicar o modelo matemático proposto por Page para expressar o comportamento da desidratação osmótica da banana da terra obtiveram um coeficiente de determinação entre $98,7 \%$ e 99,8\%.

Avaliando os coeficientes obtidos pelo ajuste do modelo de Henderson \& Pabis (Tabela 3) observou-se que este modelo ajustou-se satisfatoriamente aos dados experimentais, apresentando coeficientes de determinação maiores que $99,23 \%$ e desvio médio quadrático menor que 3,52 para todas as temperaturas.
Na Tabela 4 percebe-se que os parâmetros "a1", "a2", "a3", "a4" e "a5", utilizados para ajustes matemáticos apresentaram, de maneira geral, comportamento aleatório; contudo, o modelo de Cavalcanti Mata representa os dados experimentais na ordem superior a 98,23\% (coeficientes de determinação) e seus desvios médios quadráticos são menores que 3,45, para todas as temperaturas. Marques et al. (2007) avaliaram que o modelo proposto por Cavalcanti Mata aplicado a secagem de caju com pré-tratamento osmótico nas temperaturas de 50,60 e $70{ }^{\circ} \mathrm{C}$ foi o que melhor se ajustou aos dados experimentais.

Tabela 3 - Coeficientes obtidos pelo ajuste do modelo de Henderson \& Pabis aos dados experimentais da secagem dos cladódios de palma forrageira, nas temperaturas de 50 e $60{ }^{\circ} \mathrm{C}$.

\begin{tabular}{|c|c|c|c|c|}
\hline \multirow{2}{*}{ Formulação } & \multicolumn{2}{|c|}{ Parâmetros } & \multirow{2}{*}{$\mathrm{R}^{2}(\%)$} & \multirow{2}{*}{ DQM } \\
\hline & $\mathrm{a}$ & $\mathrm{k}$ & & \\
\hline $50{ }^{\circ} \mathrm{C}-50^{\circ}$ Brix $-1: 1$ & 1,0047 & 0,0017 & 0,9983 & 1,6235 \\
\hline $50^{\circ} \mathrm{C}-50^{\circ}$ Brix $-1: 4$ & 1,0290 & 0,0021 & 0,9975 & 3,2026 \\
\hline $50{ }^{\circ} \mathrm{C}-50^{\circ}$ Brix $-1: 10$ & 1,0183 & 0,0024 & 0,9990 & 1,6133 \\
\hline $50{ }^{\circ} \mathrm{C}-60^{\circ}$ Brix $-1: 1$ & 1,0375 & 0,0026 & 0,9988 & 1,5147 \\
\hline $50^{\circ} \mathrm{C}-60^{\circ}$ Brix $-1: 4$ & 1,0100 & 0,0022 & 0,9994 & 0,1077 \\
\hline $50{ }^{\circ} \mathrm{C}-60^{\circ}$ Brix $-1: 10$ & 1,0043 & 0,0019 & 0,9994 & 1,2887 \\
\hline $60{ }^{\circ} \mathrm{C}-50^{\circ}$ Brix $-1: 1$ & 1,0712 & 0,0030 & 0,9935 & 3,5138 \\
\hline $60^{\circ} \mathrm{C}-50^{\circ}$ Brix $-1: 4$ & 1,0434 & 0,0027 & 0,9965 & 1,3060 \\
\hline $60^{\circ} \mathrm{C}-50^{\circ}$ Brix $-1: 10$ & 1,0091 & 0,0026 & 0,9986 & 1,5570 \\
\hline $60^{\circ} \mathrm{C}-60^{\circ}$ Brix $-1: 1$ & 1,0459 & 0,0019 & 0,9984 & 2,2299 \\
\hline $60^{\circ} \mathrm{C}-60^{\circ}$ Brix $-1: 4$ & 1,0289 & 0,0022 & 0,9984 & 1,6439 \\
\hline $60^{\circ} \mathrm{C}-60^{\circ}$ Brix $-1: 10$ & 1,0152 & 0,0022 & 0,9984 & 1,6323 \\
\hline
\end{tabular}

Tabela 4 - Coeficientes obtidos pelo ajuste do modelo de Cavalcanti-Mata aos dados experimentais da secagem de palma forrageira, nas temperaturas de 50 e $60{ }^{\circ} \mathrm{C}$.

\begin{tabular}{|c|c|c|c|c|c|c|c|c|}
\hline \multirow{2}{*}{ Formulação } & \multicolumn{6}{|c|}{ Parâmetros } & \multirow{2}{*}{$\begin{array}{l}\mathrm{R}^{2} \\
(\%)\end{array}$} & \multirow{2}{*}{ DQM } \\
\hline & a1 & $\mathrm{b}$ & a2 & a3 & $\mathrm{a} 4$ & a5 & & \\
\hline $50^{\circ} \mathrm{C}-50^{\circ}$ Brix $-1: 1$ & 0,5046 & 0,0016 & 1,0614 & 0,5046 & 1,0614 & $-0,0077$ & 0,9872 & 0,4079 \\
\hline $50{ }^{\circ} \mathrm{C}-50{ }^{\circ} \mathrm{Brix}-1: 4$ & 0,3236 & 0,0011 & 0,9905 & 0,7738 & 1,0959 & $-0,0949$ & 0,9993 & 0,7243 \\
\hline $50^{\circ} \mathrm{C}-50^{\circ}$ Brix $-1: 10$ & $-2,5357$ & 0,0026 & 0,5605 & 1,7436 & 0,8619 & 1,7823 & 0,9994 & 0,0045 \\
\hline $50{ }^{\circ} \mathrm{C}-60{ }^{\circ}$ Brix $-1: 1$ & 0,2960 & 0,0010 & 0,4468 & 0,9659 & 1,1606 & $-0,2498$ & 0,9996 & 0,2167 \\
\hline $50^{\circ} \mathrm{C}-60^{\circ}$ Brix $-1: 4$ & 0,4976 & 0,0026 & 0,9921 & 0,5314 & 0,9534 & $-0,0135$ & 0,9994 & 0,1067 \\
\hline $50^{\circ} \mathrm{C}-60^{\circ}$ Brix $-1: 10$ & 0,8547 & 0,0019 & 1,0113 & 0,3334 & 0,7758 & $-0,1814$ & 0,9994 & 0,1362 \\
\hline $60^{\circ} \mathrm{C}-50^{\circ}$ Brix $-1: 1$ & 0,4161 & 0,0005 & 1,2997 & 0,5835 & 1,2953 & 0,0193 & 0,9989 & 0,4703 \\
\hline $60^{\circ} \mathrm{C}-50^{\circ}$ Brix $-1: 4$ & 0,7273 & 0,0006 & 1,2683 & 0,2251 & 1,2666 & 0,0466 & 0,9994 & 0,5943 \\
\hline $60^{\circ} \mathrm{C}-50^{\circ}$ Brix $-1: 10$ & 0,7344 & 0,0012 & 1,1360 & 0,2443 & 1,0914 & 0,0042 & 0,9996 & 0,2697 \\
\hline $60^{\circ} \mathrm{C}-60^{\circ} \mathrm{Brix}-1: 1$ & 0,5993 & 0,0013 & 1,0005 & 0,6128 & 1,0203 & $-0,1865$ & 0,9990 & 0,3090 \\
\hline $60{ }^{\circ} \mathrm{C}-60^{\circ} \mathrm{Brix}-1: 4$ & 0,4747 & 0,0263 & 0,4476 & 1,3705 & 0,5305 & $-0,6252$ & 0,9823 & 3,4054 \\
\hline $60^{\circ} \mathrm{C}-60^{\circ}$ Brix $-1: 10$ & 2,8855 & 0,0283 & 0,6827 & $-1,8051$ & 0,7820 & $-0,0307$ & 0,9990 & 0,0120 \\
\hline
\end{tabular}


Tabela 5 - Coeficientes obtidos pelo ajuste do modelo Exponencial de Dois Termos aos dados experimentais da secagem dos cladódios de palma forrageira, nas temperaturas de 50 e $60{ }^{\circ} \mathrm{C}$.

\begin{tabular}{|c|c|c|c|c|c|c|}
\hline \multirow{2}{*}{ Formulação } & \multicolumn{4}{|c|}{ Parâmetros } & \multirow{2}{*}{$\begin{array}{c}\mathrm{R}^{2} \\
(\%)\end{array}$} & \multirow{2}{*}{ DQM } \\
\hline & $\mathrm{a}$ & $\mathrm{k}_{0}$ & $\mathrm{~b}$ & $\mathrm{~K}_{1}$ & & \\
\hline $50{ }^{\circ} \mathrm{C}-50^{\circ}$ Brix $-1: 1$ & 0,5086 & 0,0024 & 0,5097 & 0,0024 & 0,9990 & 1,6108 \\
\hline $50^{\circ} \mathrm{C}-50^{\circ}$ Brix $-1: 4$ & 0,5148 & 0,0021 & 0,5142 & 0,0021 & 0,9975 & 3,2149 \\
\hline $50{ }^{\circ} \mathrm{C}-50^{\circ} \mathrm{Brix}-1: 10$ & 0,5022 & 0,0017 & 0,5021 & 0,0017 & 0,9983 & 1,6412 \\
\hline $50^{\circ} \mathrm{C}-60^{\circ}$ Brix $-1: 1$ & 0,5172 & 0,0026 & 0,5203 & 0,0025 & 0,9988 & 1,4991 \\
\hline $50^{\circ} \mathrm{C}-60^{\circ}$ Brix $-1: 4$ & 0,4098 & 0,0039 & 0,6153 & 0,0017 & 0,9989 & 1,7976 \\
\hline $50{ }^{\circ} \mathrm{C}-60^{\circ}$ Brix $-1: 10$ & 0,4992 & 0,0018 & 0,4992 & 0,0018 & 0,9993 & 0,5686 \\
\hline $60^{\circ} \mathrm{C}-50^{\circ}$ Brix $-1: 1$ & 0,5358 & 0,0030 & 0,5354 & 0,0030 & 0,9935 & 3,5299 \\
\hline $60^{\circ} \mathrm{C}-50^{\circ}$ Brix $-1: 4$ & 0,3374 & 0,0045 & 0,7227 & 0,0023 & 0,9951 & 0,9966 \\
\hline $60^{\circ} \mathrm{C}-50^{\circ}$ Brix $-1: 10$ & 0,5043 & 0,0026 & 0,5048 & 0,0026 & 0,9986 & 1,5786 \\
\hline $60^{\circ} \mathrm{C}-60^{\circ}$ Brix $-1: 1$ & 0,6424 & 0,0022 & 0,3728 & 0,0022 & 0,9965 & 2,2456 \\
\hline $60^{\circ} \mathrm{C}-60^{\circ}$ Brix $-1: 4$ & 0,5116 & 0,0022 & 0,5116 & 0,0023 & 0,9984 & 1,8349 \\
\hline $60^{\circ} \mathrm{C}-60^{\circ}$ Brix $-1: 10$ & 0,5208 & 0,0019 & 0,5251 & 0,0019 & 0,9984 & 1,6512 \\
\hline
\end{tabular}

Na Tabela 5, se observa que o modelo Exponencial de Dois termos se ajustou satisfatoriamente aos dados experimentais apresentando coeficientes de determinação maiores que $99,35 \%$ e desvio médio quadrático menor que 3,53 , para todas as temperaturas.

Analisando a Tabela 6, percebe-se que o modelo de Midilli foi o que melhor se ajustou aos dados experimentais da secagem convectiva da palma forrageira, apresentando coeficientes de determinação maiores que $99,94 \%$ e desvio médio quadrático menor que 1,49 , para todas as temperaturas.
A combinação do pré-tratamento osmótico com a secagem convectiva da palma forrageira mostrou-se adequada para obtenção de um produto diferenciado e com baixo teor de água, portanto, com características de estabilidade. Souza Neto et al. (2005) submetendo a manga a desidratação osmoconvectiva, encontraram um produto com características semelhantes.

Na Tabela 7 encontram-se as médias dos parâmetros de cor $\left(\mathrm{L}^{*}\right)$, atividade de água (aw) e textura para o cladódio da palma forrageira in natura e para todas as formulações estudadas.

Tabela 6 - Coeficientes obtidos pelo ajuste do modelo de Midilli aos dados experimentais da secagem dos cladódios de palma forrageira, nas temperaturas de 50 e $60^{\circ} \mathrm{C}$.

\begin{tabular}{|c|c|c|c|c|c|c|}
\hline \multirow{2}{*}{ Formulação } & \multicolumn{4}{|c|}{ Parâmetros } & \multirow{2}{*}{$\begin{array}{c}\mathrm{R}^{2} \\
(\%)\end{array}$} & \multirow{2}{*}{ DQM } \\
\hline & $\mathrm{a}$ & $\mathrm{k}$ & $\mathrm{n}$ & $\mathrm{b}$ & & \\
\hline $50{ }^{\circ} \mathrm{C}-50{ }^{\circ}$ Brix $-1: 1$ & 1,0016 & 0,0016 & 1,0633 & $-0,00001$ & 0,9993 & 0,4091 \\
\hline $50^{\circ} \mathrm{C}-50^{\circ}$ Brix $-1: 4$ & 0,9997 & 0,0010 & 1,1028 & $-0,00002$ & 0,9994 & 0,3961 \\
\hline $50^{\circ} \mathrm{C}-50^{\circ}$ Brix $-1: 10$ & 1,0008 & 0,0021 & 0,9414 & $-0,00007$ & 0,9993 & 0,2639 \\
\hline $50^{\circ} \mathrm{C}-60^{\circ}$ Brix $-1: 1$ & 1,0137 & 0,0012 & 1,1252 & 0,00002 & 0,9996 & 0,8477 \\
\hline $50{ }^{\circ} \mathrm{C}-60{ }^{\circ}$ Brix $-1: 4$ & 1,0174 & 0,0028 & 0,9642 & $-0,00001$ & 0,9994 & 0,0491 \\
\hline $50^{\circ} \mathrm{C}-60^{\circ}$ Brix $-1: 10$ & 1,0063 & 0,0021 & 0,9803 & $-0,00001$ & 0,9994 & 0,6458 \\
\hline $60^{\circ} \mathrm{C}-50^{\circ} \mathrm{Brix}-1: 1$ & 1,0108 & 0,0003 & 1,4034 & 0,00004 & 0,9995 & 1,4848 \\
\hline $60{ }^{\circ} \mathrm{C}-50{ }^{\circ}$ Brix $-1: 4$ & 0,1409 & 0,1409 & 0,1409 & 0,14090 & 0,9997 & 0,1409 \\
\hline $60^{\circ} \mathrm{C}-50^{\circ}$ Brix $-1: 10$ & 0,0045 & 0,7068 & 1,0040 & 0,00030 & 0,9997 & 0,0092 \\
\hline $60^{\circ} \mathrm{C}-60^{\circ}$ Brix $-1: 1$ & 1,0171 & 0,0009 & 1,1051 & $-0,00004$ & 0,9994 & 0,1199 \\
\hline $60{ }^{\circ} \mathrm{C}-60^{\circ}$ Brix $-1: 4$ & 0,9961 & 0,0008 & 1,1619 & 0,00001 & 0,9998 & 0,0682 \\
\hline $60^{\circ} \mathrm{C}-60^{\circ}$ Brix $-1: 10$ & 0,9877 & 0,0010 & 1,1211 & $-0,00001$ & 0,9994 & 0,0726 \\
\hline
\end{tabular}

Analisando a Tabela 7 , verificou-se que a cor $\left(\mathrm{L}^{*}\right)$ do cladódio da palma in natura é de 63,57, valor que se aproxima mais de 100 , ou seja, da cor branca. O tratamento 8 $\left(50{ }^{\circ} \mathrm{C}-50{ }^{\circ}\right.$ Brix $\left.-1: 4\right)$ foi o que apresentou cor $\left(\mathrm{L}^{*}\right)$ mais próxima do cladódio in natura, enquanto o tratamento 5 (60 ${ }^{\circ} \mathrm{C}-60{ }^{\circ}$ Brix - 1:4) apresentou a luminosidade mais distante, com $\mathrm{L}^{*}=46,21$.

De maneira geral constatou-se que a secagem a $50{ }^{\circ} \mathrm{C}$ apresentou uma melhor preservação da cor do cladódio de palma do que a secagem a $60{ }^{\circ} \mathrm{C}$, ou seja, quanto maior foi a temperatura de secagem, maior foi o efeito sobre a coloração do produto. Tonon et al. (2009) trabalharam com secagem de açaí e verificaram que o aumento da temperatura resultou em pós com menor luminosidade, o que pode estar relacionado à maior retirada de água (menor umidade), que resultou em produtos um pouco mais concentrados e, consequentemente, mais escuros.

Outro parâmetro muito importante para caracterizar um produto submetido à desidratação osmótica e secagem convectiva, e que é diretamente alterado é a atividade de água. O cladódio da palma forrageira in natura possui uma alta atividade de água, com uma média de 0,991, valor também verificado por Gusmão et al. (2014), estudando a elaboração da farinha dos cladódios de palma forrageira. Quanto às formulações utilizadas, observou-se que o tratamento $12\left(50{ }^{\circ} \mathrm{C}-60{ }^{\circ} \mathrm{Brix}-1: 1\right)$ apresentou a menor atividade de água que foi de 0,517 , enquanto o tratamento 4 $\left(60{ }^{\circ} \mathrm{C}-60{ }^{\circ}\right.$ Brix $\left.-1: 10\right)$ apresentou a maior atividade de 
água $(0,825)$. Gusmão et al. (2014) obtiveram valores de atividade de água que variaram de 0,26 a 0,97 ao avaliarem a atividade de água do cladódio da palma forrageira submetida à secagem em 40, 50 e $60{ }^{\circ} \mathrm{C}$. Já Souza Neto et al. (2005) encontraram valores de atividade de água em torno de 0,72 para mangas submetidas a secagem e desidratação osmótica.

Tabela 7 - Médias dos parâmetros de cor, $\mathrm{a}_{\mathrm{w}}$ e textura dos cladódios de palma submetidos à desidratação osmo-convectiva.

\begin{tabular}{lccc}
\hline Tratamentos & Cor $\left(\mathrm{L}^{*}\right)$ & $\mathrm{a}_{\mathrm{w}}$ & Textura (N) \\
\hline Amostra in natura & $63,57^{\circ}$ & 0,991 & 13,33 \\
1) $60^{\circ} \mathrm{C}-50^{\circ}$ Brix - $1: 10$ & $72,25^{\mathrm{a}}$ & $0,75^{\mathrm{bc}}$ & $51,49^{\mathrm{d}}$ \\
2) $60^{\circ} \mathrm{C}-50^{\circ}$ Brix - $1: 4$ & $55,85^{\mathrm{g}}$ & $0,58^{\mathrm{e}}$ & $86,00^{\mathrm{b}}$ \\
3) $60^{\circ} \mathrm{C}-50^{\circ}$ Brix - $1: 1$ & $50,97^{\mathrm{h}}$ & $0,54^{\mathrm{fg}}$ & $83,41^{\mathrm{b}}$ \\
4) $60^{\circ} \mathrm{C}-60^{\circ}$ Brix - $1: 10$ & $55,29^{\mathrm{g}}$ & $0,82^{\mathrm{a}}$ & $42,22^{\mathrm{de}}$ \\
5) $60^{\circ} \mathrm{C}-60^{\circ}$ Brix - $1: 4$ & $46,21^{\mathrm{i}}$ & $0,71^{\mathrm{cd}}$ & $42,04^{\mathrm{e}}$ \\
6) $60^{\circ} \mathrm{C}-60^{\circ}$ Brix - $1: 1$ & $55,84^{\mathrm{g}}$ & $0,72^{\mathrm{bcd}}$ & $46,12^{\mathrm{de}}$ \\
7) $50^{\circ} \mathrm{C}-50^{\circ}$ Brix - $1: 10$ & $68,11^{\mathrm{b}}$ & $0,76^{\mathrm{b}}$ & $96,83^{\mathrm{a}}$ \\
8) $50^{\circ} \mathrm{C}-50^{\circ}$ Brix - $1: 4$ & $62,24^{\mathrm{d}}$ & $0,57^{\text {ef }}$ & $89,45^{\mathrm{b}}$ \\
9) $50^{\circ} \mathrm{C}-50^{\circ}$ Brix - $1: 1$ & $59,39^{\mathrm{e}}$ & $0,56^{\mathrm{ef}}$ & $85,84^{\mathrm{b}}$ \\
10) $50^{\circ} \mathrm{C}-60^{\circ}$ Brix - $1: 10$ & $65,85^{\mathrm{c}}$ & $0,72^{\mathrm{bcd}}$ & $65,25^{\mathrm{c}}$ \\
11) $50^{\circ} \mathrm{C}-60^{\circ}$ Brix - $1: 4$ & $57,47^{\mathrm{f}}$ & $0,69^{\mathrm{d}}$ & $70,47^{\mathrm{c}}$ \\
12) $50^{\circ} \mathrm{C}-60^{\circ}$ Brix - $1: 1$ & $68,81^{\mathrm{b}}$ & $0,52^{\mathrm{g}}$ & $90,12^{\mathrm{ab}}$ \\
\hline
\end{tabular}

Médias com as mesmas letras, em uma mesma coluna, não diferem estatisticamente entre si $(\mathrm{p}<0,05)$ pelo teste de Tukey.

Ainda analisando a Tabela 7, notou-se que o aumento da proporção cladódio/solução ocasionou o aumento da atividade de água, ou seja, quanto menor foi a proporção cladódio/solução utilizada na desidratação osmótica, menor foi a atividade de água do produto. Constatou-se também que a atividade de água foi maior na concentração de $60^{\circ} \mathrm{Brix}$, ou seja, o aumento da concentração de solutos proporcionou um aumento na atividade de água. Resultado inverso foi verificado por Gonçalves e Blume (2008), que à medida que aumentaram a concentração de Brix, observaram redução da atividade de água na desidratação osmótica do abacaxi.

Quanto à textura, foi feito o teste de corte e determinado a força de resistência ao corte para cada um dos 12 tratamentos estudados e para o cladódio da palma in natura. A força utilizada para o corte do cladódio in natura foi, em média, de 13,32 N. Entre as formulações, a maior força de corte foi de $90,12 \mathrm{~N}$, verificada no tratamento $12\left(50{ }^{\circ} \mathrm{C}-60\right.$ ${ }^{\circ}$ Brix - 1:1) e a menor foi de $42,04 \mathrm{~N}$, verificada no tratamento $5\left(60{ }^{\circ} \mathrm{C}-60{ }^{\circ}\right.$ Brix - 1:4).

Percebeu-se que nas amostras desidratadas em concentração de $60{ }^{\circ}$ Brix, quanto menor foi a proporção cladódio/solução na desidratação, maior foi a força utilizada para o corte dos cladódios submetidos à secagem. Na concentração de 50 ${ }^{\circ}$ Brix o comportamento não foi influenciado pela proporção. Constatou-se que nas amostras desidratadas na temperatura de $50{ }^{\circ} \mathrm{C}$ a força utilizada para o corte foi maior que na temperatura de $60{ }^{\circ} \mathrm{C}$ para todas as formulações. Em razão desses resultados pode-se afirmar que a textura foi modificada pelas condições de desidratação e pela temperatura de secagem.

\section{CONCLUSÕES}

Na desidratação osmótica da palma forrageira verificouse que quanto maior a proporção cladódio/solução maior a perda de massa em ambas as concentrações. Observou-se ainda que o ganho de sólidos foi maior para a concentração de $60{ }^{\circ}$ Brix.

Verificou-se que quanto menor a proporção de cladódio/solução em que o cladódio foi desidratado, menor a razão de umidade durante a secagem convectiva. Verificou-se também que na concentração de $50{ }^{\circ}$ Brix a razão de umidade foi menor.

Todos os modelos se ajustaram bem aos dados experimentais da cinética de secagem do cladódio da palma forrageira, apresentando coeficientes de determinação $\left(\mathrm{R}^{2}\right)$ superiores a 0,99. O modelo de Midilli apresentou os menores valores de desvio médio quadrático médio (DQM) inferiores a 0,5 .

Os parâmetros de cor, atividade de água e textura foram modificados pelas condições de desidratação osmótica e de secagem as quais o cladódio da palma forrageira foi submetido. Constatou-se ainda que o cladódio desidratado a $50{ }^{\circ} \mathrm{C}$ apresentou melhor preservação da cor, maior resistência ao corte e menor atividade de água.

\section{REFERÊNCIAS BIBLIOGRÁFICAS}

ALMEIDA, C. A.; GOUVEIA, J. P. G.; ALMEIDA, F. A. C.; SILVA, F. L. H. Avaliação da cinética de secagem em frutos de acerola. Revista de Biologia e Ciências da Terra. v. 6, n. 1, 2006.

BETANCOURT-DOMÍNGUEZ, M. A.; HERNÁNDEZPÉREZ, T.; GARCÍA-SAUCEDO, P.; PAREDESLÓPEZ, O. Physico-chemical changes in cladodes (nopalitos) from cultivated and wild cacti (Opuntia spp.). Plant Foods for Human Nutrition, v. 61, n. 3, p. 115-119, 2006.

CAVAlCANTI MATA, M. E. R. M.; DANTAS, L. A. Modelo de simulação de secagem de cacau (Theobroma cacao L.) em camada fixa. Revista Brasileira de Armazenamento, Campina Grande, v. 23, n. 2, p. 5260, 1998.

CHOUGUI, N.; DJERROUD, N.; NARAOUI, F.; HADJAL, S.; ALIANE, K.; ZEROUAL, B.; LARBAT, R. Physicochemical properties and storage stability of margarine containing Opuntia ficus-indica peel extract as antioxidant. Food Chemistry, v.173, p.382-390, 2015. 
CORRÊA, J. L. G; SILVA FILHO, E. D.; BATISTA, M. B; AROLA, F.; FIOREZE, R. Desidratação osmótica de tomate seguida de secagem. Revista Brasileira de Produtos Agroindustriais, v. 10, n. 1, p. 35-42, 2008.

DIONELLO, R.G. Secagem de fatias de abacaxi in natura e pré-desidratadas por imersão-impregnação: cinética e avaliação de modelos. Revista Ciência e Tecnologia de Alimentos, vol.29, n.1, p. 2009.

FERRARI, C.C.; RODRIGUES, L. K.; TONON, R. V.; HUBINGER, M. D. Cinética de transferência de massa de melão desidratado osmoticamente em soluções de sacarose e maltose. Ciência Tecnologia de Alimentos, Campinas, v. 25, no. 3, p. 564- 570, 2005.

FERREIRA, M. F. P.; PENA, R. S. Estudo da secagem da casca do maracujá amarelo. Revista Brasileira de Produtos Agroindustriais, Campina Grande, v.12, n.1, p.15-28, 2010.

GONÇALVES, A. A.; BLUME, A. R. Efeito da desidratação osmótica como tratamento preliminar na secagem do abacaxi. Estudos Tecnológicos, v. 4, n. 2, p. 124-134, 2008.

GUSMÃO, R. P.; GUSMÃO, T. A. S.; FALCÃO FILHO, R. S.; EL AOUAR, A. A. Efeito da secagem convectiva no conteúdo de carotenóides totais e atividade de água da palma forrageira (Opuntia ficus indica Mill). Revista Brasileira de Produtos Agroindustriais, Campina Grande, v.16, n.2, p.205-212, 2014.

HENDERSON, S. M.; PABIS, S. Grain drying theory. I. Temperature effect on drying coefficient. Journal of Agriculture Engineering Research, v.6, n.3 p.169-174, 1961.

INSTITUTO ADOLFO LUTZ - Normas Analíticas; métodos químicos e físicos para a análise de alimentos. 4 ed. São Paulo: Instituto Adolfo Lutz, 2008.

LIMA, A. K. V. O.; GOMES, J. P.; SILVA, F. L. H.; SANTANA, M. F. S.; PEREIRA, F. C. Caracterização físico-química de umbuzadas formuladas com palma forrageira. Revista Brasileira de Produtos Agroindustriais, Campina Grande, v.14, n.4, 2012.

MARQUES, L. F.; DUARTE, M. E. M.; CAVALCANTI MATA, M. E. R. M.; NUNES, L. S.; COSTA, T. L.; COSTA, P. B. S.; DUARTE, S. T. G. Secagem precedida de desidratação osmótica de pseudofruto de caju: comparação entre modelos matemáticos aplicados. Revista Brasileira de Produtos Agroindustriais, v.9, n.2, p.161-170, 2007.

MAYOR, L.; SERENO, A. M. Modelling shrinkage during convective drying of food materials: a review. Journal of Food Engineering, Essex, England, v. 61, n. 3, p. 373-386, 2003.

MEDEIROS, C. D.; CAVALCANTI, J. A; ALSINA, O. L. S. Estudo da desidratação osmótica da fruta da palma (figo da Índia). Revista Brasileira de Produtos Agroindustriais, Campina Grande, v.8, n.2, p.153-162, 2006.

MIDILLI, A.; KUCUK, H.; YAPAR, Z. A new model for single-layer drying. Drying Technology, Philadelphia, v.20, n.7, p.1503-1513, 2002.
PAGE, G. E. Factors influencing the maximum rates of air drying shelled corn in thin layers. West Lafayette: Purdue University, 1949.

PONTES, S. F. O.; BONOMO, R. C. F.; PONTES, L. V.; RIBEIRO, A. C.; CARNEIRO, J. C. S. Secagem e avaliação sensorial de banana da terra. Revista Brasileira de Produtos Agroindustriais, v.9, n.2, p.143148, 2007

PORTO, M. A. L.; GUERRA, N. B.; VASCONCELOS, M. A. S.; SIQUEIRA, A. M. O.; ANDRADE, S. A. C. Otimização da desidratação osmótica de uva Crimson Seedless. Revista Ciência Agronômica, v. 45, n. 2, p. 249-256, 2014.

QI, H.; LE MAGUER, M.; SHARMA, S. K. Design and selection of processing conditions of a pilot scale contactor for continuous osmotic dehydration of carrots. Journal of Food Process Engineering, Westport, Connecticut, US, v. 21, n. 1, p. 75-88, 1998.

RAMÍREZ-MORENO, E.; CORDOBA-DÍAZ, M.; SÁNCHEZ-MATA, M.; MARQUÉS, C. D.; GONI, I. The addition of cladodes (Opuntia ficus indica $\mathrm{L}$. Miller) to instant maize flour improves physicochemical and nutritional properties of maize tortillas. LWT- Food Science and Technology, v.62, n.1, p. 675-681, 2015.

SILVA, F. D.; CAVALCANTI MATA, M. E. R. M.; DUARTE, M. E. M.; SOUZA. J. A., SILVA, Y. C. Desidratação osmótica de banana da terra (Musa sapientum) aplicação de modelos matemáticos. Revista Brasileira de Produtos Agroindustriais, Campina Grande, Especial, n.1, p.69-76, 2003.

SOUSA, P. H. M.; MAIA, G. A.; SOUZA FILHO, M. S. M.; FIGUEIREDO, R. W.; NASSU, R T.; SOUZA NETO, M. A. Influência da concentração e da proporção fruto:xarope na desidratação osmótica de bananas processadas. Revista Ciência e Tecnologia de Alimentos, v. 23, Edição suplementar, p. 126-130, 2003.

SOUZA NETO, M. A.; MAIA, G. A.; LIMA, J. R.; FIGUEIREDO, R. W.; SOUZA FILHO, M. S. M.; LIMA, A. S. Desidratação osmótica de manga seguida de secagem convencional: avaliação das variáveis de processo. Ciência Agrotecnica, Lavras, v. 29, n. 5, p. 1021-1028, set./out., 2005.

STATSOFT, Inc. Statistica (Data Analysis Software System), version 7, 2004.

TOGRUL, I. T.; PEHLIVAN, D. Modelling of drying kinetics of single apricot. Journal of Food Engineering, v.58, n.1, p.23-32, 2003.

TONON, R.V; BRABET, C.; HUBINGER, M.D. Influência da temperatura do ar de secagem e da concentração de agente carreador sobre as propriedades físico-químicas do suco de açaí em pó. Ciência e Tecnologia de Alimentos, v. 29, n.2, 444-450, 2009.

TORREGGIANI, D.; BERTOLO, G. Osmotic PreTreatments is Fruit Processing. Cheminal, Physical and Structural Effects. Journal of Food Engineering, v. 49, p. 247-253, 2001. 